\title{
Molecular characterization of mutations associated with resistance to second-line tuberculosis drug among multidrug- resistant tuberculosis patients from high prevalence tuberculosis city in Morocco
}

Amal Oudghiri ${ }^{1,2}$, Hind Karimi ${ }^{2}$, Fouad Chetioui ${ }^{3}$, Fathiah Zakham ${ }^{1}$, Jamal Eddine Bourkadi ${ }^{4}$, My Driss Elmessaoudi ${ }^{3}$, Amin Laglaoui ${ }^{2}$, Imane Chaoui ${ }^{1 *}$ and Mohammed El Mzibri ${ }^{1}$

\begin{abstract}
Background: The emergence of extensively drug-resistant tuberculosis (XDR-TB) has raised public health concern for global TB control. Although multi drug-resistant tuberculosis (MDR- TB) prevalence and associated genetic mutations in Morocco are well documented, scarce information on XDR TB is available. Hence, the evaluation of pre-XDR and XDR prevalence, as well as the mutation status of gyrA, gyrB, rrs, tlyA genes and eis promoter region, associated with resistance to second line drugs, is of great value for better management of M/XDR TB in Morocco.

Methods: Drug susceptibility testing (DST) was performed by the proportional method for first line drugs, and then the selected MDR isolates were tested for second line drugs (Ofloxacin, Kanamycin, Amikacin and Capreomycin). Along with DST, all samples were subjected to rpoB, katG and p-inhA mutation analysis by PCR and DNA sequencing. MDR isolates as well as 30 pan-susceptible strains were subjected to PCR and DNA sequencing of gyrA, gyrB, rrs, tlyA genes and eis promoter, associated with resistance to fluoroquinolones and injectable drugs.

Results: Among the 703 analysed strains, 12.8\% were MDR; Ser531Leu and Ser315Thr being the most common recorded mutations within rpoB and katG genes associated with RIF and INH resistance respectively. Drug susceptibility testing for second line drugs showed that among the 90 MDR strains, 22.2\% (20/90) were resistant to OFX, 2.22\% (2/90) to KAN, 3. $33 \%(3 / 90)$ to AMK and $1.11 \%(1 / 90)$ to CAP. Genotypic analysis revealed that 19 MDR strains harbored mutations in the gyrA gene; the most recorded mutation being Asp91Ala accounting for 47.6\% (10/21), and 2 isolates harbored mutations in the promoter region of eis gene. No mutation was found in gyrB, rrs and tlyA genes. Moreover, none of the pan-susceptible isolates displayed mutations in targeted genes.
\end{abstract}

Conclusion: Most of mutations associated with SLD resistance occurred in gyrA gene (codons 90-94) and eis promoter region. These findings highlight the impact of mutations in gyrA on the development of fluroquinolones resistance and provide the first estimates of the proportion of pre-XDR-TB among MDR-TB cases in Morocco.

Keywords: Tuberculosis, Multi-drug resistance, Extensively drug resistance, Drug susceptibility testing, Genetic mutations, Morocco

\footnotetext{
* Correspondence: im_chaoui@yahoo.fr

'Unité de Biologie et Recherches Médicales, Centre National de l'Energie, des

Sciences et Techniques Nucléaires, BP 1382 RP, 10001 Rabat, Morocco

Full list of author information is available at the end of the article
} 


\section{Background}

Worldwide, tuberculosis (TB) remains one of the most infectious diseases and leading cause of high mortality and morbidity [1]. The situation is even made worse by the emergence of drug-resistant strains, especially multidrug resistant strains (MDR) defined as resistant to at least isoniazid (INH) and rifampin (RIF), which poses a real threat to the success of TB control programs worldwide [2]. During the last decade, a bleaker picture emerged with the discovery of the extreme form of drug resistance. Extensively drug-resistant (XDR) TB, defined as MDR with resistance to fluoroquinolones (FQs) and at least one of the three injectable second- line drugs (amikacin (AMK), kanamycin (KAN), and capreomycin $(\mathrm{CAP})$ ), has emerged and represents a great health problem for national TB programs around the world. Recent data showed that at least one case of XDR TB was reported by 117 countries by the end of 2015 [3].

Yet, when considering the burden of MDR and XDR in a given population, a significant but often overlooked category is "pre-XDR", described as MDR-TB isolates with additional resistance to either a FQ or one of the three second-line injectable drugs, but not both [4].

In Morocco, the global incidence of tuberculosis is very high, with nearly 107 new cases per 100,000 inhabitants yearly, representing about 28,000 new cases per year. Global surveys revealed that the rate of MDR strains is $1 \%$ and $8.7 \%$ among new cases and re-treated patients respectively [3].

In Morocco, as it's the case in almost developing countries, diagnosis of $\mathrm{TB}$ is mainly based on direct smear examination that lacks sensitivity, and bacterial culture on Lowenstein-Jensen (L/J) medium which is time consuming, and drug susceptibility testing (DST), which has long turnaround times, is done only on request and is limited to first line drugs.

Since the discovery of the association between mutations affecting the function and/or expression of chromosomeencoded targets and resistance to anti-tuberculosis drugs, molecular based methods have emerged as alternative tools for rapid, sensitive, faster and accurate diagnosis of TB and evaluation of the resistance status of the bacteria. Resistance to RIF and INH is well documented. The latter is mainly due to point mutations in $r p o B$ gene for RIF and in katG and $a h p C$ genes and the promoter region of $i n h A$ gene for INH. The main mechanism of resistance to FQs is point mutations in the gyrA and $\operatorname{gyr} B$ genes, encoding the two subunits of the DNA gyrase. Most mutations conferring resistance to FQs occur in a short segment termed the Quinolone Resistance Determining Region (QRDR) in the gyrA gene and less frequently in gyrB. In the gyrA gene, mutations are mostly found in codons 90 and 94, and rarely in codons 88 and 91, whereas for $\operatorname{gyr} B$ the codons affected are mainly 472 and 510 [5].
Point mutations in the rrs gene, encoding the $16 \mathrm{~S}$ rRNA subunit, are associated with resistance to injectable drugs: CAP, AMK and KAN, and are located especially between nucleotides 1400 and 1500 [6-10]. Of particular interest, 3 SNPs are mainly found in the rrs gene at positions 1401, 1402 and 1484, and displaying different resistance patterns [11]. Additionally, tlyA gene, encoding the 2'-O-methyltransferase that modifies nucleotide C1409 in helix 44 of 16S rRNA and nucleotide C1920 in helix 69 of 23S rRNA is also associated with resistance to CAP [12].

Resistance to AMK could also be a result of mutations in the promoter region of eis gene, known to enhance the intracellular survival of a related bacterium [13].

FQs and/or injectable aminoglycosides are often used in the treatment of bacterial infection other than TB. Therefore, exposure to these drugs may contribute to evolution of resistance of TB patients to these agents [14].

In Morocco, like other developing countries, and due to constraint in resources and high TB burden, resistance to FQs and injectable drugs is not tested routinely. Moreover, scarce informations are available with regard to the presence of XDR strains in Morocco [3] and mutations associated with resistance to FQs and injectable drugs. Therefore, we have planned to evaluate pre-XDR and XDR prevalence, as well as the mutation status of gyr $A$, gyr $B, r r s, t l y A$ genes and eis promoter region, associated with resistance to second line drugs (SLDs), in 703 clinical isolates from TB patients recruited in the highest TB incidence region in Morocco. The aim of this study was to assess the usefulness of these molecular tools in clinical laboratories for better management of $\mathrm{M} / \mathrm{XDR} \mathrm{TB}$ in Morocco.

\section{Methods}

\section{Clinical isolates}

This prospective study was conducted between 2010 and 2012. Clinical samples were collected in Casablanca, a city with the highest TB incidence in Morocco (139.8 per 100.000 population annually), including almost one-fifth of the total cases of TB recorded in the country according to National Anti-tuberculosis Program, Department of Health, Rabat, Morocco [15] and harboring the highest number of drug-resistant TB namely MDR-TB cases [3]. Moreover, the Reference TB Laboratory in Pasteur Institute in Casablanca receives mainly patients with failure treatment and relapses, and therefore is the appropriate Center to have enough MDR cases for SLDs resistance testing.

A total of 703 clinical isolates were collected from TB confirmed pulmonary patients and sent to Mycobacterial Laboratory at Pasteur Institute in Casablanca for direct examination according to Ziehl-Neelsen method and bacterial culture on $\mathrm{L} / \mathrm{J}$ medium. 
For each recruited patient, a questionnaire including, personal information, socio-demographic characteristics and previous treatment history, was completed.

The study protocol was approved by the Ethical Committee for Pasteur Institute of Casablanca, and written informed consent was obtained from each study subject.

\section{Drug susceptibility testing}

Cultures obtained on L/J medium were collected and then tested for DST to first line drugs: RIF and INH; and second line drugs: Ofloxacin (OFX), AMK, KAN and CAP. DST was performed using the proportional method with L/J medium [16]. The critical drug concentrations were $0.2 \mu \mathrm{g} / \mathrm{ml}$ for INH, $40 \mu \mathrm{g} / \mathrm{ml}$ for RIF, $2 \mu \mathrm{g} /$ $\mathrm{ml}$ for OFX, $40 \mu \mathrm{g} / \mathrm{ml}$ for KAN, AMK and CAP each. The critical proportion of resistant bacillus necessary to define a resistant strain is $1 \%$ for all tested drugs [17].

\section{Mycobacterium tuberculosis DNA isolation}

Scraped bacterial colonies were recovered in $400 \mu \mathrm{l}$ of distilled water and boiled at $100{ }^{\circ} \mathrm{C}$ for $10 \mathrm{~min}$ to inactivate bacteria and release the mycobacterial DNA [18, 19]. Recovered DNA was immediately used for PCR amplification or stored at $-20^{\circ} \mathrm{C}$ until use.

\section{PCR amplification}

Amplification of drug-resistant genes; rpoB, katG, inh $A$, gyrA, gyrB, rrs, eis and tlyA; was carried out by PCR using specific primers reported in Table 1.
Amplification reactions were performed in a total volume of $25 \mu$ l. The amplification mixture contained $0.5 \mathrm{mM}$ of each primer, $2.5 \mathrm{mM}$ of each dNTP (dATP, dCTP, dGTP and dTTP), $25 \mathrm{mM} \mathrm{MgCl} 2$ and 1 unit of Hotstar Taq DNA polymerase (Invitrogen) and $2 \mu \mathrm{l}$ of crude DNA sample in $1 \times$ Taq polymerase buffer. For each reaction, a negative control in which DNA template was omitted from the amplification mixture, and a positive control containing DNA from H37Rv strain, were included.

For all genes, PCR amplification was started by a denaturation at $94{ }^{\circ} \mathrm{C}$ for $7 \mathrm{~min}$. Then, forty cycles of PCR were performed with denaturation at $94{ }^{\circ} \mathrm{C}$ for $1 \mathrm{~min}$, primer annealing for $1 \mathrm{~min}$ at the corresponding $\mathrm{Tm}$ and primer extension for $1 \mathrm{~min}$ at $72{ }^{\circ} \mathrm{C}$. At the end of the last cycle, the mixture was incubated at $72{ }^{\circ} \mathrm{C}$ for $7 \mathrm{~min}$. Amplicons were visualized after electrophoretic fractionation in 1 to $2 \%$ agarose gel in $0.5 \mathrm{X}$ TBE buffer and staining with ethidium bromide.

\section{Sequencing reaction}

Amplified fragments were firstly purified using the illustra ExoProStar1-Step (GE Healthcare Life Sciences). Direct sequencing of amplicons was performed using Big Dye Terminator kit (version 3.1) (Applied Biosystem, Foster City, CA, USA) that includes dideoxynucleotides labelled with four fluorochromes of different colours. For each PCR product, both strands were sequenced, in independent reactions, using the mentioned above primers. The resulting chromatograms were manually edited to ensure sequence accuracy and added to the alignment component of MEGA 5 software.

Table 1 Primer sequences and positions used to amplify the relevant genes

\begin{tabular}{|c|c|c|c|c|c|}
\hline ATB drug & Gene & Primer & Sequence & $\mathrm{Tm}$ & Length \\
\hline \multirow[t]{2}{*}{ RIF } & \multirow[t]{2}{*}{$r p o B$} & TR 8 & 5'-TGCACGTCGCGGACCTCCA-3' & \multirow[t]{2}{*}{$58^{\circ} \mathrm{C}$} & \multirow[t]{2}{*}{$157 \mathrm{bp}$} \\
\hline & & TR 9 & 5'-TCGCCGCGATCAAGGAGT-3' & & \\
\hline \multirow[t]{4}{*}{$\mathrm{INH}$} & \multirow[t]{2}{*}{ katG } & RTB 59 & 5'-TGGCCGCGGCGGTCGACATT-3' & \multirow[t]{2}{*}{$62^{\circ} \mathrm{C}$} & \multirow[t]{2}{*}{$419 \mathrm{bp}$} \\
\hline & & RTB 36 & 5'-GGTCAGTGGCCAGCATCGTC-3' & & \\
\hline & \multirow[t]{2}{*}{$\operatorname{inh} A$} & inhA P5 & 5'-CGCAGCCAGGGCCTCGCTG-3' & \multirow[t]{2}{*}{$60^{\circ} \mathrm{C}$} & \multirow[t]{2}{*}{$246 \mathrm{bp}$} \\
\hline & & $\operatorname{inhA}$ P3 & 5'-CTCCGGTAACCAGGACTGA-3' & & \\
\hline \multirow[t]{4}{*}{ FQs } & \multirow[t]{2}{*}{ gyrA } & gyrA F & 5'-TGACATCGAGCAGGAGATGC-3' & \multirow[t]{2}{*}{$59^{\circ} \mathrm{C}$} & \multirow[t]{2}{*}{$320 \mathrm{bp}$} \\
\hline & & gyrA R & 5'-GGGCTTCGGTGTACCTCATC-3' & & \\
\hline & \multirow[t]{2}{*}{ gyrB } & gyrB F & 5'-GTGGAAATATGTTGGCCGTC-3' & \multirow[t]{2}{*}{$58^{\circ} \mathrm{C}$} & \multirow[t]{2}{*}{$413 \mathrm{bp}$} \\
\hline & & gyrB R & 5'-GTCGTTGTGAACAACGCTGTG-3' & & \\
\hline \multirow{6}{*}{$\begin{array}{l}\text { Aminoglycosides } \\
\text { /cyclic peptides }\end{array}$} & \multirow[t]{2}{*}{ rrs } & $\operatorname{rrs} F$ & 5'-GTAATCGCAGATCAGCAACG-3' & \multirow[t]{2}{*}{$58^{\circ} \mathrm{C}$} & \multirow[t]{2}{*}{$216 \mathrm{bp}$} \\
\hline & & $\operatorname{rrs} R$ & 5'-GTGATCCAGCCGCACCTT-3' & & \\
\hline & \multirow[t]{2}{*}{ tlyA } & tlyA F & 5'-GTCTCTGGCCGAACTCGAAG-3' & \multirow[t]{2}{*}{$52^{\circ} \mathrm{C}$} & \multirow[t]{2}{*}{$1000 \mathrm{bp}$} \\
\hline & & tlyA R & 5'-ATTGTCGCCCAATACTTTTTCTAC-3' & & \\
\hline & \multirow[t]{2}{*}{ eis } & eis $F$ & 5'-AAA TTC GTC GCT GAT TCT CG-3' & \multirow[t]{2}{*}{$56^{\circ} \mathrm{C}$} & \multirow[t]{2}{*}{$387 \mathrm{bp}$} \\
\hline & & eis $R$ & 5'-CGC GAC GAA ACT GAG ACC-3' & & \\
\hline
\end{tabular}




\section{Results}

A total of 703 TB patients were recruited from Pasteur Institute in Casablanca. According to demographic data, the mean age of patients was 33.38 (SD: 9.7) with extreme ages of 3 and $62,80 \%$ of TB patients were in the age group of 16-45 years old. The sex ratio was 3.2.

Patients were clinically categorized according to WHO guidelines [20]; 32.4\% (228/703) of TB patients were new cases, $12.4 \%$ (87/703) failed treatment, $25.2 \%$ (177/ 703 ) were relapsed and $4.7 \%$ (33/703) of patients were under treatment after loss to follow patients. The information regarding $25.3 \%(178 / 703)$ of patients was not available.

DST was performed for RIF and INH as first line drugs. Of the 703 strains, $68.6 \%(482 / 703)$ were RIF and/or INH resistant strains. Indeed, 28.2\% (198/703) of strains were RIF mono-resistant, 27.6\% (194/703) were INH mono-resistant and $12.8 \%$ (90/703) were MDR strains.

The 90 phenotypic MDR strains were selected for further analyses, including genotypic resistance and second line drug susceptibility testing. Genotyping resistance results of the 90 MDR strains are reported in Table 2 and revealed that 84 strains were genotypic MDR strains harboring mutations in rpoB and, katG gene or inhA gene promoter; Ser531Leu and Ser315Thr being the most common recorded mutations within $r p o B$ and kat $G$ genes respectively.

DST for SLDs showed that among the 90 MDR strains, $22.2 \%(20 / 90)$ were resistant to OFX, $2.22 \%(2 / 90)$ to KAN, 3.33\% (3/90) to AMK and 1.11\% (1/90) to CAP.

Genotypic analysis of $g y r A, g y r B, r r s, t l y A$ and eis was performed on all the 90 MDR strains, as well as 30 pansusceptible MTB isolates, results are reported in Tables 3 and 4. Overall, 19 MDR strains harbored mutations in the gyrA gene and 2 strains in the promoter region of eis gene (Table 3). No mutation was found in $g y r B$, rrs and tlyA genes.

Of the 20 phenotypic FQs (OFX) resistant strains, 19 were identified by DNA sequencing to display various mutations in the QRDR region of gyrA gene. Among the 70 susceptible isolates to OFX, 69 were found to have no mutation in the gyrA and gyrB QRDR and were considered to be wild type and one strain harbored a mutation at position 90 (Ala90Val) in gyrA gene.

Our results showed that the most recorded mutation in the QRDR region of $g y r A$ gene is the substitution of GAC > GCC at codon 94 (Asp91Ala) accounting for $47.6 \%(10 / 21)$. Other point mutations were found: TCG > CCG (Ser91Pro) in 3 cases (14.3\%), GCG > GTG (Ala90Val) and GCG > ACG (Ala90Thr) in 2 strains each (9.52\%), and GAC > AAC (Asp94Asn) and GAC > CAC (Asp94His) in 1 strain each (4.8\%). Interestingly, no strain harbored more than one amino acid change.
Table 2 Frequency of mutations identified by sequencing in the rpoB, katG genes, and inhA gene promoter of MTB isolates

\begin{tabular}{|c|c|c|c|c|c|}
\hline Gene & Position & $\begin{array}{l}\text { Type of } \\
\text { Mutation }\end{array}$ & $\begin{array}{l}\text { Amino acid } \\
\text { change }\end{array}$ & $\begin{array}{l}\text { Number of } \\
\text { isolates }\end{array}$ & Total \\
\hline \multirow[t]{9}{*}{ rрoв } & 513 & $\mathrm{CAA} \rightarrow \mathrm{CCA}$ & Glu / Pro & 1 & 84 \\
\hline & 513 & $\mathrm{CAA} \rightarrow \mathrm{CTA}$ & Glu/ Leu & 1 & \\
\hline & 516 & $\mathrm{GAC} \rightarrow \mathrm{GTC}$ & Asp / Val & 3 & \\
\hline & 516 & $\mathrm{GAC} \rightarrow \mathrm{TAC}$ & Asp / Tyr & 2 & \\
\hline & 516 & $\mathrm{GAC} \rightarrow \mathrm{CAC}$ & Asp / His & 3 & \\
\hline & 526 & $\mathrm{CAC} \rightarrow \mathrm{CGC}$ & His / Arg & 3 & \\
\hline & 526 & $\mathrm{CAC} \rightarrow \mathrm{AGC}$ & His / Ser & 4 & \\
\hline & 531 & $\mathrm{TCG} \rightarrow \mathrm{TGG}$ & Ser / Trp & 5 & \\
\hline & 531 & $\mathrm{TCG} \rightarrow \mathrm{TTG}$ & Ser / Leu & 62 & \\
\hline katG & 315 & $\mathrm{AGC} \rightarrow \mathrm{ACC}$ & Ser / Thr & 81 & \\
\hline $\begin{array}{l}\text { inhA } \\
\text { promoter }\end{array}$ & -15 & $C \rightarrow T$ & & 3 & \\
\hline
\end{tabular}

Among the 6 strains phenotypically resistant to Aminoglycosides/cyclic peptides (AMK, $n=3$; KAN, $n=2$; and CAP, $n=1$ ), only 2 exhibited mutations in the promoter region of eis gene, these 2 strains are phenotypically resistant to AMK, 1 strain harbored mutation at position 12 $(\mathrm{C}>\mathrm{T})$ and another at position $14(\mathrm{C}>\mathrm{T})$. No mutation was found in rrs and tly $A$ genes. None of the pansusceptible isolates displayed mutations in targeted genes.

Of particular interest, all genotypic pre-XDR strains, harboring mutation in gyrA or eis promoter genes, belong to the 84 genotypic MDR strains.

Other mutations considered as genetic polymorphisms and known to be not associated with drug resistance were also reported, including AGC $>$ ACC at the codon 95 (Ser95Thr) of gyrA gene occurred in 20 MDR cases and $\mathrm{A}>\mathrm{G}$ at position 33 of tlyA gene and did not confer any amino acid change. The A33G was found in all MDR isolates as well as in the 30 pan-susceptible strains.

\section{Discussion}

It is widely accepted that the knowledge of the Mycobacterium tuberculosis (MTB) resistance spectrum is important for the effective treatment of MDR- and XDR-TB. In Morocco, many studies have already investigated first line drug resistance prevalence and associated genetic mutations [21-24]. However, to our best knowledge, no study has explored the pre-XDR and XDR TB status in Morocco. Therefore, we have planned through this study to investigate the prevalence of second line drug resistance and to identify the main resistance-related mutations in the MTB strains from TB patients residing in hot spot area of TB.

Among the 703 recruited strains, 90 cases were MDR $(12.8 \%)$, which is in agreement with previously reported data in Morocco $[3,25]$. DNA genotyping showed that 
Table 3 Frequency of mutations associated with SLDs resistance in MDR MTB isolates

\begin{tabular}{|c|c|c|c|c|c|c|}
\hline ATB drug & Gene & Position & Substitution & Amino acid change & $\begin{array}{l}\text { Number of } \\
\text { isolates }\end{array}$ & Sub-total \\
\hline \multirow[t]{7}{*}{ FQs } & \multirow[t]{6}{*}{ gyrA } & \multirow[t]{2}{*}{ Codon 90} & $\mathrm{GCG} \rightarrow \mathrm{GTG}$ & Ala / Val & 2 & \multirow[t]{6}{*}{19} \\
\hline & & & $\mathrm{GCG} \rightarrow \mathrm{ACG}$ & Ala / Thr & 2 & \\
\hline & & Codon 91 & $\mathrm{TCG} \rightarrow \mathrm{CCG}$ & Ser / Pro & 3 & \\
\hline & & \multirow[t]{3}{*}{ Codon 94} & $\mathrm{GAC} \rightarrow \mathrm{GCC}$ & Asp / Ala & 10 & \\
\hline & & & $\mathrm{GAC} \rightarrow \mathrm{AAC}$ & Asp / Asn & 1 & \\
\hline & & & $\mathrm{GAC} \rightarrow \mathrm{CAC}$ & Asp / His & 1 & \\
\hline & gyrB & - & - & - & 0 & 0 \\
\hline \multirow{4}{*}{$\begin{array}{l}\text { Aminoglycosides } \\
\text { /cyclic peptides }\end{array}$} & rrs & - & - & - & 0 & 0 \\
\hline & tlyA & - & - & - & 0 & \\
\hline & \multirow[t]{2}{*}{ eis } & Position 12 & $C \rightarrow T$ & - & 1 & \multirow[t]{2}{*}{2} \\
\hline & & Position 14 & $\mathrm{C} \rightarrow \mathrm{T}$ & - & 1 & \\
\hline
\end{tabular}

mutations in RRDR region of rpoB gene and, in katG gene and inhA promoter region, are the main SNPs conferring resistance to RIF and INH, respectively, confirming previously reported data [21-23] and reaffirming the usefulness of rpoB, katG and inhA promoter mutations as predictive markers for MDR TB. Moreover, molecular analysis could be limited to rpoB516, rpoB526, rpoB531, katG315 and inhA- 15 mutations, due to their high sensitivity and spectificity, to detect MDR strains.

Many studies have reported that in vitro testing is particularly cumbersome and difficult to interpret for second-line drugs, and therefore a growing interest in rapid molecular detection methods for resistance to these drugs has been well documented [11]. In this study, DST was performed only for OFX, KAN, AMK and CAP, the results showed that among the 90 MDR strains, 26 (28.9\%) were resistant to one SLD, and no XDR strain was found. Molecular analysis showed that 19 strains have point mutations in gyrA gene and only 2 strains in the promoter region of eis gene.

FQs are the mainstay of treatment for patients with MDR and XDR TB since their inclusion in therapeutic regimens improves treatment outcome [26]. However, resistance to FQs increases the risk of failure and relapse, and hinders the success of national TB programs.

In this study, 22 strains were resistant to OFX, the only FQ tested in our TB laboratory, giving a rise to high frequency of pre-XDR strains. Molecular analysis showed that 19 strains harbored mutation in the QRDR region of
gyrA gene and no mutation in gyrB gene was observed. Overall, 6 point mutations were observed and the most common one was the D94A reported in 10 cases. Previous data reported worldwide, showed that the codon 94 is the most common mutated one, but the main mutation reported was D94G [27]. D94A is associated with low level of FQ resistance in contrast to D94G which is thought to provide the greatest advantage for the cell with regard to increased resistance and the minimum loss of fitness [28]. The polymorphism S95 $\mathrm{T}$ in gyrA gene was reported in previous studies as a marker of the evolutionary history of the organism and does not correlate with drug resistance $[29,30]$. In this study, S95 T was reported in $22.22 \%$ of MDR isolates, suggesting that the corresponding strains belong to Principal Genetic Group 1 or 2 of the M. tuberculosis complex.

Two FQs resistant isolates had no mutation neither in the QRDR of either gyrA nor in $\operatorname{gyr} B$ genes. Therefore, it is relevant to screen for mutations outside the QRDR region of gyrA and in other genes, such as $\mathrm{mfpA}$ (Rv3361c), or the active efflux pump RV2686c-Rv2687cRv2688c operon, associated with FQs resistance [31-33].

One strain that harbored mutation in the QRDR of gyrA gene was phenotypically sensitive to OFX. This discordance could be due to DST error, possibly resulting from undetected hetero-resistance.

Of particular interest, molecular approach, using DNA sequencing, have high sensitivity to detect FQ resistance

Table 4 Frequency of mutations associated with polymorphism in MDR TB isolates

\begin{tabular}{llllll}
\hline ATB drug & Gene & Position & Substitution & Amino acid change & Number of isolates \\
\hline FQs & gyrA & Codon 95 & AGC $\rightarrow$ ACC & Ser / Thr & 20 \\
& gyrB & & - & - & - \\
Aminoglycosides & rrs & & - & - & - \\
/cyclic peptides & tlyA & Position 33 & A $\rightarrow$ G & - & 90 \\
& eis & & - & 0 \\
\hline
\end{tabular}


(90\%). Our results are in agreement with previously reported results in Germany (90.6\%) [34], in France (87.5\%) [11], in India (81\%) and in South Africa (79\%) [35]. However, slightly lower prevalence was reported in China (74.5\%) [31] and in Vietnam (75.6\%) [36]. Other countries exhibit low prevalence like Philippines (32\%) and Moldova (55\%) [37].

The QRDR region of gyrA is well defined and the majority of mutations found in this region confer resistance to FQs, albeit not at the same level [5]. In contrast, mutations in $\operatorname{gyr} B$ gene are associated with low level of FQ resistance and occur less frequently than in gyrA gene, even though it's widely recommended to consider the gyrB gene mutation status when screening for XDR MTB strains [5, 27, 37, 38]. However, in Morocco, and due to limited resources and high drug resistance $\mathrm{TB}$, sequencing of the $\operatorname{gyr} B$ gene might not be a great concern for determination of FQ resistance.

Worldwide, the high prevalence of pre-XDR TB as well as the occurrence of FQ resistance within pansusceptible isolates might imply the inappropriate use of these drugs [39-41]. Indeed, FQs antibiotics (Ofloxacin, ciprofloxacin, and levofloxacin) are among the most potent SLDs used for treatment of MDR-TB. However, FQ resistant $M$. tuberculosis strains results from injudicious use of this class of drugs either in the management of MDR-TB or by excess use of these drugs in the treatment of respiratory tract infections as well as other bacterial infections, increasing the burden of selective pressure and compromising their efficacy in the treatment of TB $[42,43]$.

For injectable drugs, DST was performed for AMK, KAN and CAP, and clearly showed that resistance to these drugs is rare, and only few strains exhibited a resistant status. In the present study, genetic mutations, associated with injectable drugs resistance, were investigated in all 90 MDR MTB strains, despite their susceptible/ resistance profiles to SLDs, and in the 30 pan-susceptible strains. SNPs associated resistance were not detected neither in rrs nor in tlyA genes.

It is widely accepted that mutations within tly $A$ gene, resulting in CAP resistance, are rare and represent less than $3 \%$ of phenotypically resistant strains [12]. However, when reported, they were not found in any CAP susceptible strains, making them potentially highly specific markers of CAP resistance [44]. Of particular interest, investigation of the tlyA gene SNP revealed an A33G substitution, without any amino acid changes (Leu33Leu). This polymorphism was recently reported by Sowajassatakul et al. [45] and was found in all MDR MTB strains as well as pansusceptible strains, suggesting a clonal selection of MDR TB in Morocoo and could be used for phylogenetic studies of MDR TB strains.
Mutations in the rrs gene, encoding the 16S rRNA bacterial subunit, cause high-level resistance to KAN and cross-resistance to AMK and sometimes CAP [33], and the more prevalent mutation (A1401G), has been reported as a surrogate marker for high-level resistance to KAN and AMK [46-48]. The absence of mutations in the rrs gene among our MDR strains could be probably due to limited number of resistant isolates to injectable drugs.

Mutations within eis promoter region were reported to be largely associated with KAN resistance $[6,13]$. In the present study, the eis promoter SNP C-12 $\mathrm{T}$ was found in $1 / 2(50 \%)$ of AMK resistant strains and SNP C-14 T occurred in $1 / 3(33.33 \%)$ of KAN resistant strains, and none of the KAN and AMK sensitive strains harbored any mutation in the eis promoter region. These SNPs are very common and were considered as non-specific markers of KAN and/ou AMK resistance, as they are reported in both resistant and sensitive strains.

Available data related to mutations associated with resistance to SLD confirm that a single mutation, or even a set of mutations in a single gene, does not adequately predict phenotypic resistance to AMK, KAN and CAP. It is likely that a combination of different gene mutations for each injectable drug will be needed to best predict phenotypic resistance [9]. Based on these results, special attention is given to high rate of FQs resistance within MDR-TB and the possible reduced efficacy of drug combinations including FQs in treating MDR-TB. Unlikely, DST for SLDs is still out of reach for many low income countries that are placing MDR-TB patients on empirical treatment with a FQ without knowing the susceptible/resistance status. Available molecular tests mainly genotype MTBDRsl would add a great value for detection of SLDs resistance particularly FQs [11].

MDR-TB and XDR-TB are indicators of TB control failures; they emerge due to several reasons: (1) insufficient drug regiments for TB cases; (2) no adherence to an appropriate regimen; (3) poor quality of drugs; and (4) transmission of MDR-TB and XDR-TB in the community. The lack of data on XDR-TB trends in Morocco is mainly due to the lack of routine DST for second line anti-TB drugs.

There were no XDR strains in this collection. To the best of our knowledge, XDR MTB strains are rare in Morocco [3], but the high proportion of pre XDR-MTB strains is of concern. In this field, the identification of pre-XDR TB will be of a great interest for clinicians to monitor closely $\mathrm{TB}$ patients and forestall the progression to XDR TB which is more difficult to treat and is often associated with poor treatment success and has the potential to severely cripple global control efforts for TB.

The present study is very informative and give for the first time data on genetic mutations associated with resistance to 
second line drugs in Morocco. However, the main limitation was the small number of resistant strains to injectable drugs which may not reflect the real burden of drug resistance, especially XDR, in Morocco.

\section{Conclusion}

Most of mutations associated with SLD resistance occurred in gyrA gene (codons 90-94) and eis promoter region. Other genes namely gyrB, rrs and $t$ ly $A$ did not harbor any mutations associated with resistance to SLDs. These findings highlight the impact of mutations in gyrA on the development of FQ resistance and provide the first estimates of the proportion of pre-XDR-TB among MDR-TB cases in Morocco. Therefore, MDR TB strains must be systematically screened for $g y r A$ mutations, for rapid detection of second-line $\mathrm{TB}$ drug resistance which is of a great interest for appropriate treatment regimens and for limiting spread of drug resistant TB.

\begin{abstract}
Abbreviations
AMK: Amikacin; CAP: Capreomycin; DR-TB: Drug resistant tuberculosis: DST: Drug susceptibility testing; FLDs: First line drugs; FQ: Fluoroquinolones; HIV: Human immunodeficiency virus; INH: Isoniazid; KAN: kanamycin; L/ J: Lowenstein Jensen; MDR: Multidrug resistant; MTB: Mycobacterium tuberculosis; OFX: Ofloxacin; PCR: Polymerase chain reaction; Pre-XDR: Preextensively drug resistant; QRDR: Quinolone resistance determining region; RIF: Rifampin; SLDs: Second line drugs; SNP: Single nucleotide polymorphism; TB: Tuberculosis; TBE: Tris-Borate- EDTA; WHO: World Health Organization; XDR: Extensively drug resistant
\end{abstract}

\section{Acknowledgements}

Not applicable

\section{Funding}

This study was funded in part by the International Atomic Energy Agency under the RAF6040 project and Regional Office for the Eastern

Mediterranean/World Health organization under the RPC/RAB\&GH 10/11-03 project.

\section{Availability of data and materials}

Availability of data and materials Data supporting the conclusions of this article are included within the article. The datasets used and/or analyzed during the current study will be made available from the corresponding author on reasonable request.

\section{Authors' contributions}

Conceived and designed the study: JEB, MDE, AL, IC, MEM. Patients' recruitment: HK, JEB, MDE. Performed the experiments: AE, HK, FC, FZ, IC. Analyzed the data: FZ, AE, FC, IC. Contributed reagents/materials/analysis tools: MDE, AL, IC, MEM. Wrote the manuscript: AE, IC, MEM. All authors provided critical review of the paper. All authors read and approved the final manuscript.

\section{Ethics approval and consent to participate}

The study protocol was approved by the Ethical Committee of Pasteur Institute of Morocco, and written informed consent was obtained from each study subject.

\section{Consent for publication}

Not applicable

\section{Competing interests}

The authors declare that they have no competing interests.

\section{Publisher's Note}

Springer Nature remains neutral with regard to jurisdictional claims in published maps and institutional affiliations.

\section{Author details}

${ }^{1}$ Unité de Biologie et Recherches Médicales, Centre National de I'Energie, des Sciences et Techniques Nucléaires, BP 1382 RP, 10001 Rabat, Morocco. 'Equipe de Recherche en Biotechnologies et Génie des Biomolécules, Faculté des Sciences et Techniques de Tanger, Ancienne Route de l'Aéroport, Km 10, Ziaten, BP 416, Tanger, Morocco. ' ${ }^{3}$ Laboratoire de la Tuberculose, Institut Pasteur du Maroc, Casablanca, 1 Place Louis Pasteur, Boulevard Abdelmoumen, 20250 Casablanca, Morocco. ${ }^{4}$ Service de Pneumo-Phtisiologie, Hôpital Moulay Youssef, CHU Rabat, Avenue Sidi Mohamed Ben Abdallah, Al Akkari, Rabat, Morocco.

Received: 16 March 2017 Accepted: 22 February 2018

Published online: 27 February 2018

\section{References}

1. World Health Organization. World health statistics data. Geneva; 2009. http://www.who.int/whosis/whostat/2009/en/. Accessed 14th Apr 2017.

2. Loddenkemper $R$, Hauer B. Drug-resistant tuberculosis: a worldwide epidemic poses a new challenge. Dtsch Arztebl Int. 2010;107:10-9.

3. World Health Organization. Global Terculosis Report. Genova; 2016. http:// www.who.int/tb/publications/global_report/en/. Accessed 14th Apr 2017.

4. Banerjee R, Allen J, Westenhouse J, Oh P, Elms W, Desmond E, et al. Extensively drug resistant tuberculosis in California, 1993-2006. Clin Infect Dis. 2008:47:450-7.

5. Aubry A, Veziris N, Cambau E, Truffot-Pernot C, Jarlier V, Fisher LM. Novel gyrase mutations in quinolone-resistant and -hypersusceptible clinical isolates of Mycobacterium tuberculosis: functional analysis of mutant enzymes. Antimicrob Agents Chemother. 2006;50:104-12.

6. Ramaswamy S, Musser J. Molecular genetic basis of antimicrobial agent resistance in mycobacterium tuberculosis: 1998 update. Off J Int Union against Tuberc Lung Dis. 1998;79:3-29.

7. Alangaden GJ, Kreiswirth BN, Aouad A, Khetarpal M, Igno FR, Moghazeh SL, et al. Mechanism of resistance to amikacin and kanamycin in Mycobacterium tuberculosis. Antimicrob Agents Chemother. 1998;42:1295-7.

8. Suzuki Y, Katsukawa C, Tamaru AKl, Abe C, Makino M, Mizuguchi Y, et al. Detection of kanamycin-resistant mycobacterium tuberculosis by identifying mutations in the 165 rRNA gene. Clin Microbiol. 1998;36:1220-5.

9. Georghiou SB, Magana M, Garfein RS, Catanzaro DG, Catanzaro A, Rodwell TC. Evaluation of genetic mutations associated with Mycobacterium tuberculosis resistance to amikacin, kanamycin and capreomycin: a systematic review. PLoS One. 2012;7:e33275.

10. Ali A, Hasan Z, McNerney R, Mallard K, Hill-Cawthorne G, Coll F, et al. Whole genome sequencing based characterization of extensively drug-resistant Mycobacterium tuberculosis isolates from pakistan. PLoS One. 2015;10: e0117771.

11. Brossier F, Veziris N, Aubry A, Jarlier V, Sougakoff W. Detection by GenoType MTBDRs test of complex mechanisms of resistance to second-line drugs and ethambutol in multidrug-resistant mycobacterium tuberculosis complex isolates. J Clin Microbiol. 2010;48:1683-9.

12. Johansen SK, Maus CE, Plikaytis BB, Douthwaite $S$. Capreomycin binds across the ribosomal subunit Interface using tlyA-encoded 2'-O-methylations in 165 and 23S rRNAs. Mol Cell. 2006;23:173-82.

13. Zaunbrecher MA, Sikes RD, Metchock B, Shinnick TM, Posey JE. Overexpression of the chromosomally encoded aminoglycoside acetyltransferase eis confers kanamycin resistance in Mycobacterium tuberculosis. Mol Cell. 2009;106:20004-9.

14. Ventola $\mathrm{CL}$. The antibiotic resistance crisis: part 1: causes and threats. P T a peer-reviewed J Manag care. Hosp Formul Manag. 2015;40:277-83.

15. World Health Organization. Division of communicable diseases, surveillance. Anti-tuberculosis drug resistance in the world / the WHO/IUATLD global project on anti-tuberculosis drug resistance surveillance. Report 2, prevalence and trends. Geneva; 2000. http://www.who.int/iris/handle/10665/ 66493.Accessed 14th Apr 2017.

16. Canetti G, Froman S, Grosset J, Hauduroy P, Langerova M, Mahler HT, et al. Mycobacteria: laboratory methods for testing drug sensitivity and resistance. Bull Wld Hlth Org. 1963;29:565-78. 
17. David H, Frebault L, Thorel M. Methodes de Laboratoire pour Mycobactériologie Clinique. Unité de tuberculose et des mycobacteries. Inst Pasteur Press. 1987:87.

18. Aldous W, Pounder J, Cloud JL, Woods G. Comparison of six methods of extracting M. tuberculosis DNA from processed sputum for testing by quantitative real-time PCR. J Clin Microbiol. 2005:43:2471-3.

19. Chaoui I, Sabouni R, Kourout M, Jordaan AM, Lahlou O, Elouad R, et al. Analysis of isoniazid, streptomycin and ethambutol resistance in Mycobacterium tuberculosis isolates from Morocco. J Infect Dev Ctries. 2009; 3:278-84.

20. World Health Organization. TB manual National Tuberculosis Programme Guideline. Warsaw; 2001. http://www.euro.who.int/_data/assets/pdf_file/ 0017/123164/E75464.pdf. Accessed 14th Apr 2017.

21. Sabouni R, Kourout M, Chaoui I, Jordaan A, Akrim M, Victor TC, et al. Molecular analysis of multidrug resistant Mycobacterium tuberculosis isolates from Morocco. Ann Microbiol. 2008;58:749-54.

22. Kourout M, Chaoui I, Sabouni R, Lahlou O, El Mzibri M, Jordaan A, et al. Molecular characterisation of rifampicin-resistant Mycobacterium tuberculosis strains from Morocco. Int J Tuberc Lung Dis. 2009;13:1440-2.

23. Zakham F, Chaoui I, Echchaoui AH, Chetioui F, Elmessaoudi MD, Ennaji MM, et al. Direct sequencing for rapid detection of multidrug resistant Mycobacterium tuberculosis strains in Morocco. Infect Drug Resist. 2013;6: 207-13.

24. Chaoui I, Atalhi N, Sabouni R, Akrim M, Abid M, Amzazi S, et al. Rifoligotyping assay: an alternative method for rapid detection of rifampicin resistance in Mycobacterium tuberculosis isolates from Morocco. Biotechnol Biotechnol. Equip. Taylor \& Francis. 2014;28:1095-102.

25. World Health Organization. Global tuberculosis control: surveillance, planning, financing. Geneva; 2008. http://apps.who.int/iris/handle/10665/ 43831. Accessed 14th Apr 2017

26. Chan ED, Laurel V, Strand MJ, Chan JF, Huynh M-LN, Goble M, et al. Treatment and outcome analysis of 205 patients with multidrug-resistant tuberculosis. Am J Respir Crit Care Med. 2004;169:1103-9.

27. Feuerriegel S, Cox HS, Zarkua N, Karimovich HA, Braker K, Rüsch-Gerdes S, et al. Sequence analyses of just four genes to detect extensively drug-resistant Mycobacterium tuberculosis strains in multidrug-resistant tuberculosis patients undergoing treatment. Antimicrob Agents Chemother. 2009;53:3353-6.

28. Takiff HE, Salazar L, Guerrero C, Philipp W, Huang WM, Kreiswirth B, et al. Cloning and nucleotide sequence of Mycobacterium tuberculosis gyrA and gyrB genes and detection of quinolone resistance mutations. Antimicrob Agents Chemother. 1994;38:773-80.

29. Sreevatsan S, Pan X, Stockbauer KE, Connell ND, Kreiswirth BN, Whittam TS, et al. Restricted structural gene polymorphism in the mycobacterium tuberculosis complex indicates evolutionarily recent global dissemination. Proc Natl Acad Sci U S A. 1997;94:9869-74.

30. Soudani A, Hadjfredj S, Zribi M, Messaoud T, Masmoudi A, Majed B, et al. First report of molecular characterization of fluoroquinolone-resistant Mycobacterium tuberculosis isolates from a Tunisian hospital. Clin Microbiol Infect. 2010;16:1454-7.

31. Pasca MR, Guglierame P, Arcesi F, Bellinzoni M, De Rossi E, Riccardi G. Rv2686c-Rv2687c-Rv2688c, an ABC fluoroquinolone efflux pump in Mycobacterium tuberculosis. Antimicrob Agents Chemother. 2004;48:3175-8.

32. Mokrousov I, Otten T, Manicheva O, Potapova Y, Vishnevsky B, Narvskaya O, et al. Molecular characterization of ofloxacin-resistant mycobacterium tuberculosis strains from Russia. Antimicrob Agents Chemother. 2008;52: 2937-9.

33. Hu Y, Hoffner S, Wu L, Zhao Q, Jiang W, Xu B. Prevalence and genetic characterization of second-line drug-resistant and extensively drug-resistant Mycobacterium tuberculosis in rural china. Antimicrob Agents Chemother. 2013:57:3857-63.

34. Hillemann D, Rüsch-Gerdes S, Richter E. Feasibility of the GenoType MTBDRs/ assay for fluoroquinolone, amikacin-capreomycin, and ethambutol resistance testing of mycobacterium tuberculosis strains and clinical specimens. J Clin Microbiol. 2009:47:1767-72.

35. Hoshide M, Qian L, Rodrigues C, Warren R, Victor TC, Evasco HB, et al. Geographical differences associated with single-nucleotide polymorphisms (SNPs) in nine gene targets among resistant clinical isolates of Mycobacterium tuberculosis. J Clin Microbiol. 2014;52:1322-9.

36. Kiet VS, Lan NTN, An DD, Dung NH, Hoa DV, Chau NW, et al. Evaluation of the MTBDRsI test for detection of second-line-drug resistance in Mycobacterium tuberculosis. J Clin Microbiol. 2010;48:2934-9.
37. Wang JY, Lee LN, Lai HC, Wang SK, Jan IS, Yu CJ, et al. Fluoroquinolone resistance in Mycobacterium tuberculosis isolates: associated genetic mutations and relationship to antimicrobial exposure. J Antimicrob Chemother. 2007:59:860-5.

38. Malik S, Willby M, Sikes D, Tsodikov OV, Posey JE. New insights into fluoroquinolone resistance in Mycobacterium tuberculosis: functional genetic analysis of gyrA and gyrB mutations. PLoS One. 2012;7:e39754

39. Kumar R, Garg R, Kant S, Verma SK, Kushwaha RA, Kumar S, Jain A. High correlation of clinical criteria in the diagnosis of drug-resistant TB and prevalence of ofloxacin resistance. Int J Tuberc Lung Dis. 2016;20:1354-7.

40. Peloquin CA, Hadad DJ, Molino LP, Palaci M, Boom WH, Dietze R, et al. Population pharmacokinetics of levofloxacin, gatifloxacin, and moxifloxacin in adults with pulmonary tuberculosis. Antimicrob Agents Chemother. 2008:52:852-7.

41. Singhal R, Reynolds PR, Marola JL, Epperson LE, Arora J, Sarin R, et al. Sequence analysis of fluoroquinolone resistance-associated genes gyrA and gyrB in clinical Mycobacterium tuberculosis isolates from patients suspected of having multidrug-resistant tuberculosis in New Delhi, India. J Clin Microbiol. 2016;54:2298-305.

42. Ginsburg AS, Hooper N, Parrish N, Dooley KE, Dorman SE, Booth J, et al. Fluoroquinolone resistance in patients with newly diagnosed tuberculosis. Clin Infect Dis. 2003;37:1448-52.

43. Singla N, Gupta D, Birbian N, Singh J. Association of NAT2, GST and CYP2E1 polymorphisms and anti-tuberculosis drug-induced hepatotoxicity. Tuberculosis Elsevier Ltd. 2014:94:293-8.

44. Maus CE, Plikaytis BB, Thomas M, Shinnick TM. Mutation of tlyA confers Capreomycin resistance in mycobacterium tuberculosis. Antimicrob Agents Chemother. 2005;49:571-7

45. Sowajassatakul A, Prammananan T, Chaiprasert A, Phunpruch S. Molecular characterization of amikacin, kanamycin and capreomycin resistance in M/ XDR-TB strains isolated in Thailand. BMC Microbiol. 2014;14:165

46. Jugheli L, Bzekalava N, De Rijk P, Fissette K, Portaels F, Rigouts L. High level of cross-resistance between kanamycin, amikacin, and capreomycin among mycobacterium tuberculosis isolates from Georgia and a close relation with mutations in the rrs gene. Antimicrob Agents Chemother. 2009;53:5064-8.

47. Evans J, Segal H. Novel multiplex allele-specific PCR assays for the detection of resistance to second-line drugs in mycobacterium tuberculosis. J Antimicrob Chemother. 2010:65:897-900.

48. Yuan X, Zhang T, Kawakami K, Zhu J, Li H, Lei J, et al. Molecular characterization of multidrug- and extensively drug-resistant mycobacterium tuberculosis strains in Jiangxi, China. J Clin Microbiol. 2012;50:2404-13.

\section{Submit your next manuscript to BioMed Central and we will help you at every step:}

- We accept pre-submission inquiries

- Our selector tool helps you to find the most relevant journal

- We provide round the clock customer support

- Convenient online submission

- Thorough peer review

- Inclusion in PubMed and all major indexing services

- Maximum visibility for your research

Submit your manuscript at www.biomedcentral.com/submit
) Biomed Central 